\title{
Effects of Tetrodotoxin and Ion Replacements on the Short-circuit Current Induced by Escherichia coli Heat Stable Enterotoxin across Small Intestine of the Gerbil (Gerbillus cheesmani)
}

\author{
Fawzia Yaqoub Al-Balool
}

Department of Biological Sciences, Faculty of Science, Kuwait University, P.O. Box 5969, Safat, 13060, State of Kuwait

The effects of mucosally added Escherichia coli heat stable enterotoxin (STa $30 \mathrm{ng} \mathrm{ml}^{-1}$ ) on the basal short-circuit current (Isc in $\mu \mathrm{A} \mathrm{cm}^{-2}$ ) across stripped and unstripped sheets of jejuna and ilea taken from fed, starved (4 days, water ad lib) and undernourished (50\% control food intake for 21 days) gerbil (Gerbillus cheesmani) were investigated. The effect of neurotoxin tetrodotoxin $(T T X 10 \mu \mathrm{M})$ and the effects of replacing chloride by gluconate or the effects of removing bicarbonate from bathing buffers on the maximum increase in Isc induced by STa were also investigated. The maximum increase in Isc which resulted from the addition of STa were significantly higher in jejuna and ilea taken from starved and undernourished gerbils when compared with the fed control both using stripped and unstripped sheets. In the two regions of the small intestine taken from fed and starved animals TTX reduced the maximum increase in Isc induced by STa across unstripped sheets only. Moreover in jejuna and ilea taken from undernourished gerbils TTX reduced significantly the maximum increase in Isc induced by STa across stripped and unstripped sheets. Replacing chloride by gluconate decreased the maximum increase in Isc induced by STa across jejuna and ilea taken from undernourished gerbils only. Removing bicarbonates from bathing buffer decreased the maximum increase in Isc across the jejuna and ilea taken from starved and undernourished gerbils.

Key words: Escherichia coli - heat atable enterotoxin - chloride replacement - gluconate - bicarbonate - gerbil

Escherichia coli heat stable enterotoxin (STa) induces secretion by rasing the concentration of cyclic GMP in the enterocyte (Field et al. 1978) which leads to electrogenic chloride secretion and inhibits elecronutral sodium chloride absorption (Guandolini et al. 1982). It has been demonstrated that the enteric nervous system is important in STa-induced secretion as shown by the inhibitory effect of neuronal blockade (Field et al. 1978, Scott et al. 1980, Eklund et al. 1986, Rolf \& Levin 1994, Nzegwu \& Levin 1996). Rolf and Levin (1999) showed that STa activates nitric oxide dependent myenteric plexus secretory reflex mediated by capsaicin sensitive C-fibers. Al-Majali et al. (2000) suggested that $\mathrm{Na}^{+} / \mathrm{Cl}^{-}$coupling may be the major mechanism for the loss of ions in the STa-induced secretory diarrhoeal response. Lucas (2001) in his review on the reconsideration of the evidence for $E$. coli STa enterotoxin-driven fluid secretion proposed a new model for the action of STa involving inhibition of $\mathrm{Na}^{+} / \mathrm{H}^{+}$exchange which explains the ability of STa to reduce absorption in vitro but its inability to cause secretion in vivo in contrast to its apparent secretory effect in vitro. The aim of the present study was to investigate whether in the desert mammals such as gerbils there is a regional differences between jejunum and ileum in their responses

Financial support: Research Administration, Kuwait University grant SZ 045

Fax: +965-4847054. E-mail: albalool@kuc01.kuniv.edu.kw Received 16 September 2003

Accepted 1 March 2004 to STa and if there is a neural involvement in such responses. The effects of replacing chloride ions by gluconate and the effects of removing bicarbonate ions from buffer media were also investigated.

\section{MATERIALS AND METHODS}

Animals and diets - Gerbils (Gerbillus cheesmani) of both sex, body weight 36-40 g, were captured from the desert in the State of Kuwait and kept in the animal house for at least three weeks before use. Three nutritional groups were used. The fed group had free access to water and food (SDS rodent diet, Essex, England) and were held in rooms maintained at $27 \pm 2{ }^{\circ} \mathrm{C}$. The lights were on from 5 am until $5 \mathrm{pm}$ and the humidity was $50 \%$. For the starved groups, water was given ad lib but the food was removed 4 days before the animals were used. The chronically undernourished group was housed in individual cages and was fed $50 \%$ of the control food intake for 21 days. Animals were housed routinely in plastic cages with wired mesh bottoms to reduce coprophagy.

Technique - On the day of use, animals were anaesthetised with thiopentone sodium $(30 \mathrm{mg} / \mathrm{kg}$ body weight, ip). When surgical anesthesia was achieved, a mid-line incision was made along the abdomen and the entire small intestine $(28-30 \mathrm{~cm})$ was removed and flushed with $0.9 \%$ $\mathrm{NaCl}$. Jejunal sheets were taken immediately distal to the ligament of Treitz and ileal sheets from the region immediately proximal to the terminal $1 \mathrm{~cm}$ of the small intestine. The intestine was used either intact (unstripped preparation) or with the outer smooth muscle layers was removed (stripped preparation). Stripping removes the myenteric plexus as well as the muscle coat but leaves intact the submucosal and mucosal plexus (Andres et al. 1985). Each segment was then cut open and mounted as a flat sheet 
between two plates over an aperture creating an exposed tissue area of approximately $0.42 \mathrm{~cm}^{2}$. The plates were clamped between two perspex chambers and the measurements of the short circuit-current (Isc in microamps) across the tissue was monitored by an automatic voltage clamp (DVC 200, WPI Inc., Stevenage, UK). The chambers (7.5 $\mathrm{ml}$ ) were filled with bicarbonate saline, $\mathrm{pH} 7.4$ (Krebs \& Heinseleit 1932) which contained (mM) $143 \mathrm{Na}^{+}, 125.7 \mathrm{Cl}$, $24.9 \mathrm{HCO}_{3}^{-}, 5.9 \mathrm{~K}^{+}, 2.5 \mathrm{Ca}^{2+}, 1.2 \mathrm{H}_{2} \mathrm{PO}_{4}, 1.2 \mathrm{SO}_{4}^{2}, 1.2$ $\mathrm{Mg}^{2+}$. The medium was maintained at $38^{\circ} \mathrm{C}$ and gassed with humidified $95 \% \mathrm{O}_{2}, 5 \% \mathrm{CO}_{2}$.

The short-circuit current (Isc in $\mu \mathrm{A} \mathrm{cm}{ }^{-2}$ ) was measured by a previously published standard technique (Baldwin \& Levin 1985). The mounted tissue was allowed to stabilise for $10 \mathrm{~min}$ and the Isc was measured (basal reading). STa (30 $\mathrm{ng} \mathrm{ml}^{-1}$ ) were added to the mucosal solution and then the maximal increase in the Isc was monitored. In some experiments tetrodotoxin $(10 \mu \mathrm{M})$ was added to the serosal solution $10 \mathrm{~min}$ before the addition of the STa with the control sheets receiving an equivalent volume of vehicle.

In experiments investigating the ion replacement, all the chloride ions in the bicarbonate saline were replaced with isoosmolar solutions of sodium, potassium, and calcium gluconate. In the bicarbonates freeconditions, Krebs phosphate buffer oxygenated with $100 \% \mathrm{O}_{2}$ was used on both sides of the tissue. All gerbils were killed by thoracotomy at the end of the experiments. Co Ltd.

All chemicals were purchased from Sigma Chemical

Statistical analysis The results are shown as the mean \pm SE. Statistical comparisons were accomplished using unpaired student's t test with 0.05 as the level of significance.

\section{RESULTS}

Effects of STa on Isc across the jejunum and the ile$u m$ - The maximum increase in Isc which resulted from addition of STa $\left(30 \mathrm{ng} \mathrm{ml}^{-1}\right)$ to the mucosal bathing solution are shown in Table I. In fed jejunum the maximum increase in Isc which results from addition of STa were not significantly different in stripped and unstripped sheets. Similarly in fed ilea there were not much differences in the maximum increase in Isc induced by STa be- tween stripped and unstripped sheets. Comparing the two regions of the small intestine the maximum increase in Isc induce by STa were not significantly different in jejuna and ilea when using both stripped or unstripped sheets. Starvation increased significantly the maximum increase in Isc induced by STa in both stripped and unstripped sheets of the two regions of the small intestine. Using unsripped sheets the maximum increases in Isc induced by STa in starved jejunum were double that of the stripped ones. Reducing the food intake to half for 21 days increased significantly the maximum Isc generated by STa when compared with the fed control in both jejunum and ileum using either stripped or unstripped sheets. In both regions of the small intestine the percent increase in the maximum increases in Isc generated by STa in the unstripped sheets were double that in the stripped sheets.

Effects of TTX on the maximum Isc responses by STa The effects of TTX $(10 \mu \mathrm{M})$ placed in the serosal bathing solution, 10 min before the addition of STa on the maximum increases in Isc generated by STa are shown in Table II. In fed jejunum and ileum TTX reduced significantly the maximum increase in Isc induced by STa across the unstripped sheets only. Similarly in starved animals Isc induced by STa were inhibited by TTX in the unstripped sheet of both jejunum and ileum. However, in the jejuna and ilea taken from undernourished gerbils TTX reduced significantly the maximum increase in Isc generated by STa using both stripped and unstripped sheets.

Effects of replacing chloride ions by gluconate on the STa responses in Isc - Replacing chloride in the bathing buffer by gluconate has no significant effects on the maximum increase in Isc induced by STa in jejunum and ileum taken from fed and starved animals both using stripped and unstripped sheets. However, in the jejuna and ilea taken from undernourished gerbils the maximum increases in Isc induced by STa were significantly inhibited by replacing chloride in the bathing buffer by gluconate (Table III).

Effects of removing bicarbonate from bathing buffer on STa responses in Isc - Removing bicarbonate from bathing buffer has no significant effects on the maximum increases in Isc induced by STa across stripped and unstripped sheets taken from fed animals. On the other hand removing bicarbonate from bathing buffer decreased

TABLE I

Effects of starvation and undernourishment on the maximum increase in short-circuit current (Isc) induced by heat stable enterotoxin (STa) (30 $\left.\mathrm{n} \mathrm{ml}^{-1}\right)$ across stripped and unstripped sheets of jejunum and ileum

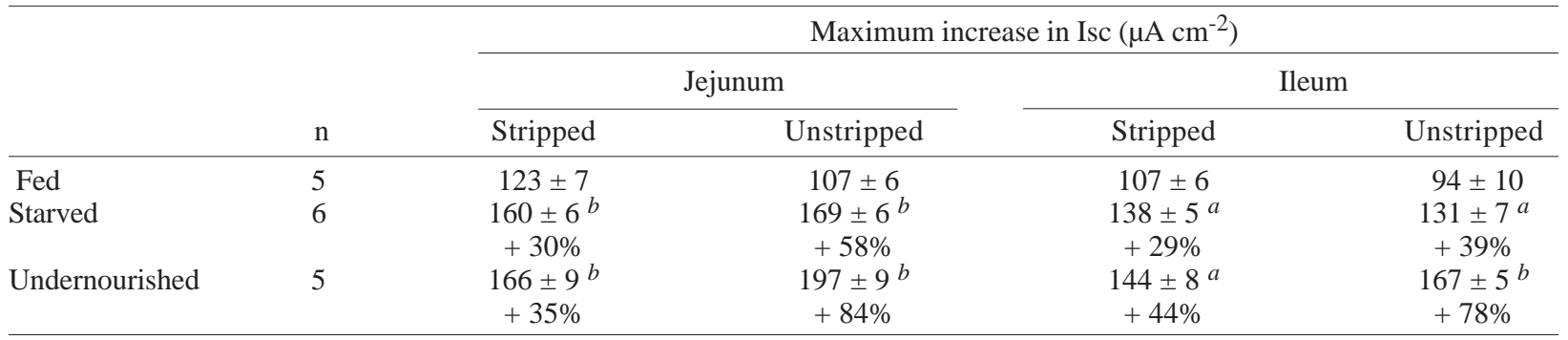

All values express as mean \pm SEM $\%$ changes and statistical significance (unpaired t test) are for starved or undernourished against the fed group; $a: \mathrm{p} \leq 0.05 ; b: \mathrm{p} \leq 0.001$ 
TABLE II

Effect of tetrodotoxin (TTX) on the maximum increase in short-circuit current (Isc) induced by heat stable enterotoxin (STa) across stripped and unstripped sheets of jejunum and ileum from fed, starved, and undernourished gerbils

\begin{tabular}{|c|c|c|c|c|c|}
\hline & \multirow[b]{3}{*}{$\mathrm{n}$} & \multicolumn{4}{|c|}{ Maximum increase in Isc $\left(\mu \mathrm{A} \mathrm{cm}^{-2}\right)$} \\
\hline & & \multicolumn{2}{|c|}{ Jejunum } & \multicolumn{2}{|c|}{ Ileum } \\
\hline & & Stripped & Unstripped & Stripped & Unstripped \\
\hline \multicolumn{6}{|l|}{ Fed } \\
\hline Control & 6 & $123 \pm 7$ & $107 \pm 6$ & $107 \pm 6$ & $94 \pm 10$ \\
\hline TTX & 5 & $102 \pm 6$ & $\begin{array}{l}84 \pm 6^{a} \\
-21 \%\end{array}$ & $97 \pm 5$ & $\begin{array}{l}61 \pm 5^{a} \\
-35 \%\end{array}$ \\
\hline \multicolumn{6}{|l|}{ Starved } \\
\hline Control & 6 & $160 \pm 6$ & $169 \pm 6$ & $138 \pm 5$ & $131 \pm 7$ \\
\hline TTX & 5 & $165 \pm 5$ & $\begin{array}{l}144 \pm 8^{a} \\
-15 \%\end{array}$ & $109 \pm 7$ & $\begin{array}{l}97 \pm 7^{a} \\
-26 \%\end{array}$ \\
\hline \multicolumn{6}{|c|}{ Undernourished } \\
\hline Control & 6 & $166 \pm 9$ & $197 \pm 9$ & $144 \pm 8$ & $167 \pm 5$ \\
\hline TTX & 5 & $\begin{array}{l}86 \pm 7^{b} \\
-48 \%\end{array}$ & $\begin{array}{c}117 \pm 9^{b} \\
-42 \%\end{array}$ & $\begin{array}{l}67 \pm 3^{b} \\
-53 \%\end{array}$ & $\begin{array}{l}91 \pm 8^{c} \\
-46 \%\end{array}$ \\
\hline
\end{tabular}

All values express as mean \pm SEM $\%$ changes and statistical significance (unpaired t test) are given for test groups against control; $a: \mathrm{p} \leq 0.05 ; b: \mathrm{p} \leq 0.01 ; c: \mathrm{p} \leq 0.001$

TABLE III

Effect of replacing chloride ions by gluconate on the maximum increase in short-circuit current (Isc) induced by heat stable enterotoxin (STa) across stripped and unstripped sheets of jejunum and ileum from fed, starved and undernourished gerbils

\begin{tabular}{|c|c|c|c|c|c|}
\hline & \multirow[b]{3}{*}{$\mathrm{n}$} & \multicolumn{4}{|c|}{ Maximum increase in Isc $\left(\mu \mathrm{A} \mathrm{cm}^{-2}\right)$} \\
\hline & & \multicolumn{2}{|c|}{ Jejunum } & \multicolumn{2}{|c|}{ Ileum } \\
\hline & & Stripped & Unstripped & Stripped & Unstripped \\
\hline \multicolumn{6}{|l|}{ Fed } \\
\hline Chloride present & 5 & $123 \pm 7$ & $107 \pm 6$ & $107 \pm 6$ & $94 \pm 10$ \\
\hline $\begin{array}{l}\text { Gluconate replacement } \\
\text { of chloride }\end{array}$ & 5 & $144 \pm 8$ & $95 \pm 5$ & $122 \pm 4$ & $113 \pm 8$ \\
\hline \multicolumn{6}{|l|}{ Starved } \\
\hline Chloride present & 6 & $160 \pm 6$ & $169 \pm 6$ & $138 \pm 5$ & $131 \pm 7$ \\
\hline $\begin{array}{l}\text { Gluconate replacement } \\
\text { of chloride }\end{array}$ & 5 & $146 \pm 3$ & $152 \pm 3$ & $119 \pm 3$ & $117 \pm 2$ \\
\hline \multicolumn{6}{|l|}{ Undernourished } \\
\hline Chloride present & 5 & $166 \pm 9$ & $197 \pm 9$ & $144 \pm 8$ & $167 \pm 5$ \\
\hline $\begin{array}{l}\text { Gluconate replacement } \\
\text { of chloride }\end{array}$ & 4 & $\begin{array}{l}115 \pm 6^{a} \\
-31 \%\end{array}$ & $\begin{array}{c}112 \pm 12^{a} \\
-43 \%\end{array}$ & $\begin{array}{c}107 \pm 3^{a} \\
-44 \%\end{array}$ & $\begin{array}{c}86 \pm 12^{a} \\
-49 \%\end{array}$ \\
\hline
\end{tabular}

All values express as mean \pm SEM $\%$ changes and statistical significance (unpaired t test) are given for test groups against control; $a$ : $\mathrm{p} \leq 0.001$

significantly the maximum increases in Isc taken from starved and undernourished gerbils by the same magnitude in both conditions and in the two regions (Table IV).

\section{DISCUSSION}

The results of the present study showed that $E$. coli STa elicits an electrogenic secretion measured as Isc in jejuna and ilea taken from fed, starved and undernourished gerbils. It also showed that the maximum values for such increases were significantly higher in starved and undernourished intestine when compared with their fed control. In fed gerbils there were no significant differences in the STa responses between the two regions and there were no significant differences between stripped and unstripped preparations. Therefore, it can be sug- gested that in fed gerbils STa has a direct action on enterocytes. In addition there were no significant differences between the two regions. This disagrees with the results of Al-Majali et al. (2000) who found that both the number of receptors and their affinity to STa were higher on ileal epithelium than other intestinal segments of the newborn calves. Other studies in humans, avians and rats (Cohen et al. 1986, Nobles et al. 1991, Kraus et al. 1994, $1995)$ suggested that the number of STa receptors decreases on intestinal enterocytes prepared from the distal parts of the small intestine.

Starving gerbils for 4 days or reducing food intake to half for 21 days increased significantly the maximum responses in Isc induced by STa in the small intestine. This is in agreement with other studies using different animals 
TABLE IV

Effect of removing bicarbonate from bathing buffer on the maximum increase in short-circuit current (Isc) induced by heat stable enterotoxin (STa) across jejunum and ileum from fed, starved, and undernourished gerbils

\begin{tabular}{|c|c|c|c|c|c|}
\hline & \multirow[b]{3}{*}{$\mathrm{n}$} & \multicolumn{4}{|c|}{ Maximum increase in Isc $\left(\mu \mathrm{A} \mathrm{cm}^{-2}\right)$} \\
\hline & & \multicolumn{2}{|c|}{ Jejunum } & \multicolumn{2}{|c|}{ Ileum } \\
\hline & & Stripped & Unstripped & Stripped & Unstripped \\
\hline \multicolumn{6}{|l|}{ Fed } \\
\hline Bicarbonate present & 5 & $123 \pm 7$ & $107 \pm 6$ & $107 \pm 6$ & $94 \pm 10$ \\
\hline Bicarbonate absent & 5 & $118 \pm 2$ & $122 \pm 1$ & $106 \pm 5$ & $94 \pm 2$ \\
\hline \multicolumn{6}{|l|}{ Starved } \\
\hline Bicarbonate present & 6 & $160 \pm 6$ & $169 \pm 6$ & $138 \pm 5$ & $131 \pm 7$ \\
\hline Bicarbonate absent & 5 & $\begin{array}{c}110 \pm 2^{a} \\
-31 \%\end{array}$ & $\begin{array}{l}115 \pm 5^{a} \\
-32 \%\end{array}$ & $\begin{array}{l}95 \pm 2^{a} \\
-31 \%\end{array}$ & $\begin{array}{l}90 \pm 4^{a} \\
-31 \%\end{array}$ \\
\hline \multicolumn{6}{|l|}{ Undernourished } \\
\hline Bicarbonate present & 5 & $166 \pm 9$ & $197 \pm 13$ & $145 \pm 8$ & $167 \pm 5$ \\
\hline Bicarbonate absent & 5 & $\begin{array}{c}113 \pm 2^{a} \\
-32 \%\end{array}$ & $\begin{array}{c}114 \pm 12^{a} \\
-42 \%\end{array}$ & $\begin{array}{c}101 \pm 2^{a} \\
-30 \%\end{array}$ & $\begin{array}{l}101 \pm 2^{a} \\
-40 \%\end{array}$ \\
\hline
\end{tabular}

All values express as mean \pm SEM $\%$ changes and statistical significance (unpaired t test) are given for test groups against control; $a$ : $\mathrm{p} \leq 0.001$

(Young et al.1988, Young \& Levin 1990, Chohen et al. 1992, Carey et al. 1994). The present study showed that starvation increases the Isc generated by STa across the jejunum both using stripped and unstripped preparations but the percent increases using the unstripped sheets were double that of the stripped ones. Similarly the percent increase which results from undernourishment in the unstripped sheets were also double that of the stripped sheets both in the jejunum and ileum. Therefore in the gerbil like in the rat (Nzegwu \& Levin 1994) dietary deprivation in the form of starvation and undernourishment enhanced the maximum elecrogenic secretion due to STa presences. The differences between stripped and unstripped sheets is that in the unstripped sheets both the submucosal and the myenteric plexus were present whereas in the stripped only the submucosal plexii was present. Thus in gerbil, the increase in the Isc induced by STa which results from starvation and undernourishment, are more in the unstripped sheets. This is may be due to the presences of the two type of plexii.

It has been shown that the enteric nervous system is involved in STa induced secretion as demonstrated by the inhibitory effect of hexamethonium, lidocaine, tetrodotoxin, and capsaicin (Eklund et al. 1985, Rolf et al. 1992, Rolf \& Levin 1994). In a previous study (Al-Balool, manuscript in preparation) on the effects of TTX on the basal Isc, it was found that in fed gerbils the neural component of the basal Isc was more obvious in the jejunum than in the ileum. It also showed that dietary deprivation can induce or uncover a neural path in the enteric nervous system that activates the basal intestinal secretion. In fed gerbil TTX reduced significantly the maximum increase in Isc induced by STa across the unstripped sheets only. This is in agreement with the results of Rolf and Levin (1994) who found that in rat TTX significantly reduced the maximum increase in Isc induced by STa in unstripped but not the stripped ilea. Similar to the fed intestine, in starved jejunum and ileum TTX reduced significantly the maximum increase in Isc induced by STa only in the unstripped sheets. However, TTX reduced significantly the maximum increase in Isc induced by STa using both stripped and unstripped preparations of jejuna and ilea taken from undernourished intestine. It can be suggested that the raise in the maximum increases in Isc induced by STa across the unsripped preparation in the fed and starved gerbils could be derived by TTX-sensitive neural circuit in the submucosal and in the myenteric plexii of the enteric nervous system. However, the elevation in the maximum increase in Isc induced by STa across the stripped sheets of jejunum and ileum taken from undernourished intestine are driven by submucosal plexii only. Therefore, in gerbils small intestine STa exhibited intestinal secretion by affecting the submucosal plexus (stripped sheets) and both submucosal and myenteric plexus (unstripped sheets).

In a previous study (Al-Balool 2004) it was shown that the basal Isc across the jejuna and ilea taken from starved and undernourished gerbils were more sensitive than those taken from fed animals when chloride was replaced by gluconate or when bicarbonate were removed from bathing buffers. Replacing chloride in the buffer media by gluconate did not change the maximum increase in Isc induced by STa in both regions of the small intestine taken from fed and starved animals. However, it decreased significantly the maximum increase in Isc induced by STa in both regions taken from undernourished animals using both stripped and unstripped sheets. Moreover, removing bicarbonate from buffer media decreased significantly the maximum increase in Isc induced by STa in both regions of the small intestine taken from starved and undernourished gerbils only and were without any effect on those taken from fed animals. Thus it can be suggested that part of the elevation in the maximum increase in Isc induced by STa in starved animals were bi- 
carbonate dependent, while such elevation in the undernourished gerbils were chloride and bicarbonate dependent.

Therefore, it can be concluded that in gerbils small intestine (i) starvation and undernourishment raised the maximum increases in Isc induced by STa; (ii) STa has a direct effect on enterocytes as well as through neural mechanism as shown by the inhibitory action of TTX; (iii) part of the elevation in the Isc produced by STa in the small intestine taken from starved gerbils were bicarbonate dependent while in the undernourished animals the elevation in Isc induced by STa was chloride and bicarbonate dependent.

\section{REFERENCES}

Al-Balool FY 2004. Effects of starvation and undernourishment on some electrical parameters of the small intestine of the desert gerbil (Gerbillus cheesmani). Kuwait J Sci Eng (in press).

Al-Majali AM, Asem EK, Lamar CH, Robinson JP, Freeman MJ, Saeed A 2000. Characterization of the interaction of Escherichia coli heat-stable enterotoxin (STa) with its putative receptor on the intestinal tract of newborn calves. FEMS Immunol Med Microbiol 28: 97-104.

Andres H, Bock R, Bridge RJ, Rummel W, Schreiner J 1985. Submucosal plexus and electrolyte transport across rat colonic mucosa. J Physiol 364: 301-312.

Baldwin D, Levin RJ 1985. Electrogenic currents induced by secretagogues and glucose across proximal and distal rat duodenum and jejunum in vitro. IRCS Med Sci 13: 269-270.

Carey HV, Hayden UL, Tucker KE 1994. Fasting alters basal and stimulated ion transport in piglet jejunum. Am J Physiol Regul Integr Comp Physiol 267: R156-63.

Cohen MB, Moyer MS, Luttrell M, Giannella RA 1986. The immature rat small intestine exhibits an increased sensitivity and response to Escherichia coli heat-stable enterotoxin. Pediatr Res 20: 555-560.

Cohen MB, Nogueira J, Laney DW, Conti Jr TR 1992. The jejunal secretory response to Escherichia coli heat-stable enterotoxin is prolonged in malnourished rat. Pediatr Res 31: 228-233.

Eklund S, Jodal M, Lundgren O 1985. The enteric nervous system participates in the secretory response to the heat stable enterotoxins of Escherichia coli in rats and cats. Neuroscience 14: 673-681.

Eklund S, Jodal M, Lundgren O 1986. The net fluid secretion caused by cyclic 3' 5 '- guanosine monophosphate in rat jejunum in vivo is mediated by a local nervous reflex. Acta Physiol Scand 128: 57-63.

Field M, Graf LH, Laired Jr. WJ, Smith PL 1978. Heat-stable enterotoxin of Escherichia coli: In vitro effects on guanylate cyclase activity, cyclic GMP concentration, and ion trans- port in small intestine. Proc Natl Acad Sci USA 75: 28002804.

Guandolini A, Rao MC, Smith PL, Field M 1982. Cyclic GMP modulation of ion transport in rabbit ileum; studies with heat-stable Escherichia coli enterotoxin. Am J Physiol Gastrointest Liver Physiol 253: G775-G780.

Kraus WJ, Cullingford GL, Freeman RH, Eber SL, Richardson KC, Fok KF, Currie MG, Forte LR 1994. Distribution of heat-stable enterotoxin/guanylin receptors in the intestinal tract of man and other mammals. J Anat 194: 407-417.

Kraus WJ, Freeman RH, Eber SL, Hamra FK, Fok KF, Currier MG, Forte LR 1995. Distribution of the Escherichia coli heat-stable enterotoxin/guanylin receptors in the avian intestinal tract. Acta Anat 153: 210-219.

Krebs HA, Heinseleit K 1932.Untersuchunger uber die harnestoff-bildung im tierkorper. Hoppe-seyler's Z Physio Chem 210: 33-66.

Lucas MI 2001. A reconsideration of the evidence for Escherichia coli STa (heat stable) enterotoxin-driven fluid secretion:a new view of STa action and a new paradigm for fluid absorption. J Appl Microbiol 90: 7-26.

Nobles M, Diener M, Rummel W 1991. Segment-specific effects of the heat-stable enterotoxin of Escherichia coli on electrolyte transport in the rat colon. Eur J Pharmacol 202: 201-211.

Nzegwu HC, Levin RJ 1994. Role of the enteric nervous system in the maintained hypersecretion induced by enterotoxin STa in the nutritionally deprived intestine. Gut 35: 1237-1243.

Nzegwu HC, Levin RJ 1996. Luminal capsaicin inhibits fluid secretion induced by enterotoxin $E$. coli STa but not by carbachol, in vivo in rat small and large intestine. Exp Physiol 81: 313-315.

Rolf VE, Levin RJ 1994. Enterotoxin E. coli STa activates a nitric oxide-dependent myenteric plexus secretory reflex in the rat ileum. J Physiol (Lond) 475: 531-537.

Rolf VE, Levin RJ 1999. Vagotomy inhibits the jejunal fluid secretion activated by luminal ileal Escherichia coli STa in the rat in vivo. Gut 44: 615-619.

Rolf VE, Levin RJ, Young A 1992. Electrogenic secretion in rat intestine in vitro activated by $E$. coli STa is not mediated by local release of 5-hydroxytryptamine. J Physiol 446: 107.

Scoot A, Forsyth GW, Kapitany RA, Roe WE, Hamilton DL 1980 . Effects of isolated heat-stable enterotoxin produced by Escherichia coli on fluid secretion and cyclic nucleotide level in the ejunum of weanling pig. Can J Physiol Pharmacol 58: 772-777.

Young A, Levin RJ 1990. Diarrhoea of famine and malnutrition: investigations using a rat model. 1 - Jejunal hypersecretion induced by starvation. Gut 31: 43-53.

Young A, Pereira MC, Warren MA, Levin RJ 1988. Hypersecretion associated with the action of Escherichia coli STa enterotoxin on the jejunum and ileum from starved and chronically undernourished rats. Medl Sci Res 16: 573-574. 